\title{
LETTERS
}

\section{No borders during the post-glacial assembly of European bryophytes}

\author{
A. Ledent, ${ }^{1, a}$ A. Désamoré, ${ }^{2, a}$ \\ B. Laenen, ${ }^{2, a}$ P. Mardulyn, ${ }^{3}$ \\ S. F. McDaniel, ${ }^{4}$ F. Zanatta, ${ }^{1}$ \\ J. Patiño $0^{5,6, a}$ and \\ A. Vanderpoorten ${ }^{1, a *}$
}

\begin{abstract}
Climatic fluctuations during the Last Glacial Maximum (LGM) exerted a profound influence on biodiversity patterns, but their impact on bryophytes, the second most diverse group of land plants, has been poorly documented. Approximate Bayesian computations based on coalescent simulations showed that the post-glacial assembly of European bryophytes involves a complex history from multiple sources. The contribution of allochthonous migrants was $95-100 \%$ of expanding populations in about half of the 15 investigated species, which is consistent with the globally balanced genetic diversities and extremely low divergence observed among biogeographical regions. Such a substantial contribution of allochthonous migrants in the post-glacial assembly of Europe is unparalleled in other plants and animals. The limited role of northern micro-refugia, which was unexpected based on bryophyte life-history traits, and of southern refugia, is consistent with recent palaeontological evidence that LGM climates in Eurasia were much colder and drier than what palaeoclimatic models predict.
\end{abstract}

\section{Keywords}

Bryophytes, climate change, dispersal, historical biogeography, Last Glacial Maximum, refugia.

Ecology Letters (2019)

\section{INTRODUCTION}

Pleistocene glacial cycles, ending c. 19000 years ago at the Last Glacial Maximum (LGM), played a major role in structuring the distribution of biodiversity (Lumibao et al. 2017). During glacial maxima, ice made vast areas inaccessible for most plant and animal species to establish (Eidesen et al. 2013). In Europe, palaeontological and phylogeographic evidence suggest that species currently distributed in ice-free areas at LGM either persisted in southern refugia (Hewitt 1999, 2000, 2004; Médail \& Diadema 2009) or in micro-refugia located in the steppe zone South of the ice sheet (Bhagwat \& Willis 2008). During warmer periods, like the current interglacial, populations expanded northward from southern refugia or northern micro-refugia, generating admixed populations with high genetic diversity at mid-latitudes, and genetically depauperate populations at high latitudes resulting from long-distance dispersal events and associated founder effects (Hewitt 1999; Petit et al. 2003).

For species currently distributed in areas that were covered in ice at LGM, Darwin (1859) and Hooker (1862) similarly proposed that species migrated southwards with the advancing ice sheets. Although this hypothesis received some support (Schönswetter et al. 2006; Skrede et al. 2006), this explanation is incomplete. For example, palaeontological evidence suggests that lowland areas south of the ice sheet experienced a cold and dry climate that was unsuitable for Arctic and Alpine floras (Abbott \& Brochmann 2003). It is possible that some species survived in local micro-refugia within the ice-sheet area in the Arctic (Westergaard et al. 2011) or in southern mountain ranges, from where they potentially back-colonised northern areas (Schönswetter et al. 2003, 2005). However, Hultén (1937) alternatively suggested that ice-free regions of Beringia, a region encompassing north-east Russia and north-west America, served as a source for the recolonisation of Europe (Eidesen et al. 2013).

The ability of species to persist in northern refugia can be predicted from their life-history traits, which include, in woody plant species, short generation times, small seed sizes and vegetative reproduction under harsh environmental conditions (Bhagwat \& Willis 2008). Such traits precisely characterise bryophytes, a diverse and conspicuous component of terrestrial ecosystems. In particular, the successful regeneration of subglacial bryophytes following hundreds to thousands of years of ice entombment (La Farge et al. 2013; Roads et al. 2014; Cannone et al. 2017), along with phylogeographic evidence for in situ persistence of moss species in Antarctica during the LGM (Pisa et al. 2013; Biersma et al. 2018), broadens the concept of glacial refugia, traditionally confined to survival of land plants beyond glacier margins. Bryophyte

\footnotetext{
${ }^{1}$ Institute of Botany, University of Liege, Sart Tilman, 4000 Liege, Belgium ${ }^{2}$ Department of Ecology, Environment, and Plant Sciences, Science for Life Laboratory, Stockholm University, Stockholm, Sweden

${ }^{3}$ Evolutionary Biology \& Ecology, Université Libre de Bruxelles, 1050 Brussels, Belgium

${ }^{4}$ Biology Department, University of Florida, Gainesville, FL 32611, USA
}

\footnotetext{
${ }^{5}$ Plant Conservation and Biogeography Group, Departamento de Botánica, Ecología y Fisiología Vegetal, Universidad de La Laguna, 38071 La Laguna, Spain

${ }^{6}$ Island Ecology and Evolution Research Group, Instituto de Productos Naturales y Agrobiología (IPNA-CSIC), 38071 La Laguna, Spain

*Correspondence: E-mail: a.vanderpoorten@uliege.be

${ }^{a}$ Equal contribution.
} 
diaspores are, however, capable of extreme long-distance dispersal, further raising the intriguing idea that the post-glacial recolonisation of Europe might have taken place from extraEuropean sources (Kyrkjeeide et al. 2014) such as North America (Stenøien et al. 2011) and Macaronesia (Hutsemékers et al. 2011; Laenen et al. 2011; Patiño et al. 2015).

The rich macrofossil record preserved in lake sediments and peat has provided a detailed picture of the Quaternary bog flora (Jakab \& Sümegi 2011), but we lack a more global, community-scale understanding of the post-glacial recolonisation of Europe by bryophytes. Molecular phylogeography has increasingly appeared as a promising tool in historical biogeography, especially since model-based methods under a formal framework have overcome the limitations of the qualitative description of summary statistics or gene trees (Thomé \& Carstens 2016). The high dispersal capacities of bryophytes have, however, casted doubt on the possibility to find signatures of historical demographic events from analyses of their extant spatial genetic patterns (Van der Velde \& Bijlsma 2003). Spore-trapping experiments indeed revealed that a higher proportion of spores originates from sources farther away than the nearest sources, leading to an inverse isolation effect (Sundberg 2005) erasing any isolation-bydistance signal (Szövényi et al. 2012).

Here, we applied approximate Bayesian computations (ABCs) in the framework of the coalescent theory and combined them with predictions from species distribution models (Fig. 1) to address the following questions:

Can patterns of genetic structure and diversity be used to retrace the post-glacial history of European bryophytes, or did intense post-glacial migrations erase any spatial genetic structure, making it impossible to retrace the origin of migrants? If a significant genetic structure exists, which historical scenario best fits with the observed patterns of genetic structure and diversity? Given bryophyte life-history traits, we hypothesise that northern refugia or even populations buried under the ice sheet at LGM substantially contributed to the post-glacial recolonisation of Europe.

\section{MATERIALS AND METHODS}

\section{Population and molecular sampling}

Twelve and three species with their core present distribution range in areas that were ice-free and covered in ice at LGM (hereafter, IF and IC species, respectively) were used as models (Tables 1 and 2). Specimens were sampled across the entire distribution range of the species, but with a focus on Europe and North America due to previous evidence for the existence of genetic connections between them (Szövényi et al. 2008; Stenøien et al. 2011; Kyrkjeeide et al. 2016; Désamoré et al. 2016). Each specimen was assigned to each of three or five regions (Table S1, Fig. S1), which correspond to the definition of source and sink areas for IF and IC species respectively. We used here the circumscription of continental Europe of the European Environment Agency (https://www.eea.europa.e u/data-and-maps/data/biogeographical-regions-europe-3)

(Fig. 2). In the south-east, Caucasus, which marks the border between Europe and Asia, was excluded. The extra-European range included the Holarctic, but not the Southern Hemisphere, where some of the species exhibit scattered occurrences. Indeed, while the existence of bipolar ranges attests to discrete episodes of long-distance dispersal between the Southern and Northern Hemispheres over the past million years (see Biersma et al. 2017 for review), Southern Hemisphere populations are unlikely to have contributed to the post-glacial recolonisation of Europe, given that the Equator represents a strong geographic barrier to spore migrations (McDaniel \& Shaw 2005; Vanderpoorten et al. 2010). For IF species, Europe was split into southern and northern ranges to delimitate areas that correspond to the location of northern and southern refugia, as defined, for example by Bhagwat \& Willis (2008) and Médail \& Diadema (2009) respectively. The definition of the southern refugia corresponds to the circumscription of the Mediterranean (sensu https://www.eea.eu ropa.eu/data-and-maps/data/biogeographical-regions-europe3) but including the entire Iberian Peninsula. We also assigned a few specimens from northern Africa to the Mediterranean region. For IC species, the partitioning was based on the extent of the ice sheet at LGM (Abbott \& Brochmann 2003), so that four regions were considered within Europe: 1. northern range under the ice sheet at LGM; 2a, b. ice-free and iced southern mountain ranges at LGM, respectively; 3. lowland range south of the ice sheet at LGM (Fig. 2).

We used published sequence data (Désamoré et al. 2016) and another 1941 newly produced sequences following the protocols of Désamoré et al. (2016) to expand the geographical and taxonomic sampling (Table S1). Specimens of liverworts were sequenced at 2-3 cpDNA loci including both coding and non-coding regions. For mosses, specimens were sequenced at up to $3 \mathrm{cpDNA}$ loci and 1-3 intron-spanning nuclear loci selected for their suitable range of variation from McDaniel et al. (2013) (Tables 1 and 2, Table S1). Sequences were aligned with the 'muscle' algorithm (Edgar 2004) as implemented in Seaview 4.7 (Gouy et al. 2010). Gaps were treated as missing data. In all analyses, cpDNA data were

Figure 1 Graphical abstract of the integrative method employed to reconstruct the post-glacial history of European bryophytes. (1) Sampling of specimens across their distribution range. (2) Genotyping by Sanger sequencing at selected loci, producing a matrix of observed sequence data. (3) Simulation of sequence data under competing post-glacial recolonisation scenarios (3.1). Millions of allele genealogies are simulated under alternative coalescence models, for which demographic parameters are randomly sampled from prior probability distributions before each simulation. The prior distribution of one of these demographic parameters, population size, is derived from estimates inferred from species distribution models. DNA sequence data sets equal in size to the observed data are generated by implementing nucleotide substitutions along the simulated genealogies (3.2). Observed and simulated data are summarised using summary statistics characterising population structure and genetic diversity. The distances between observed and simulated summary statistics are computed and the simulations with the 1000 shortest distances are used to generate the posterior probability distributions for all demographic parameters and identify the scenario with the highest posterior probability (PP). 


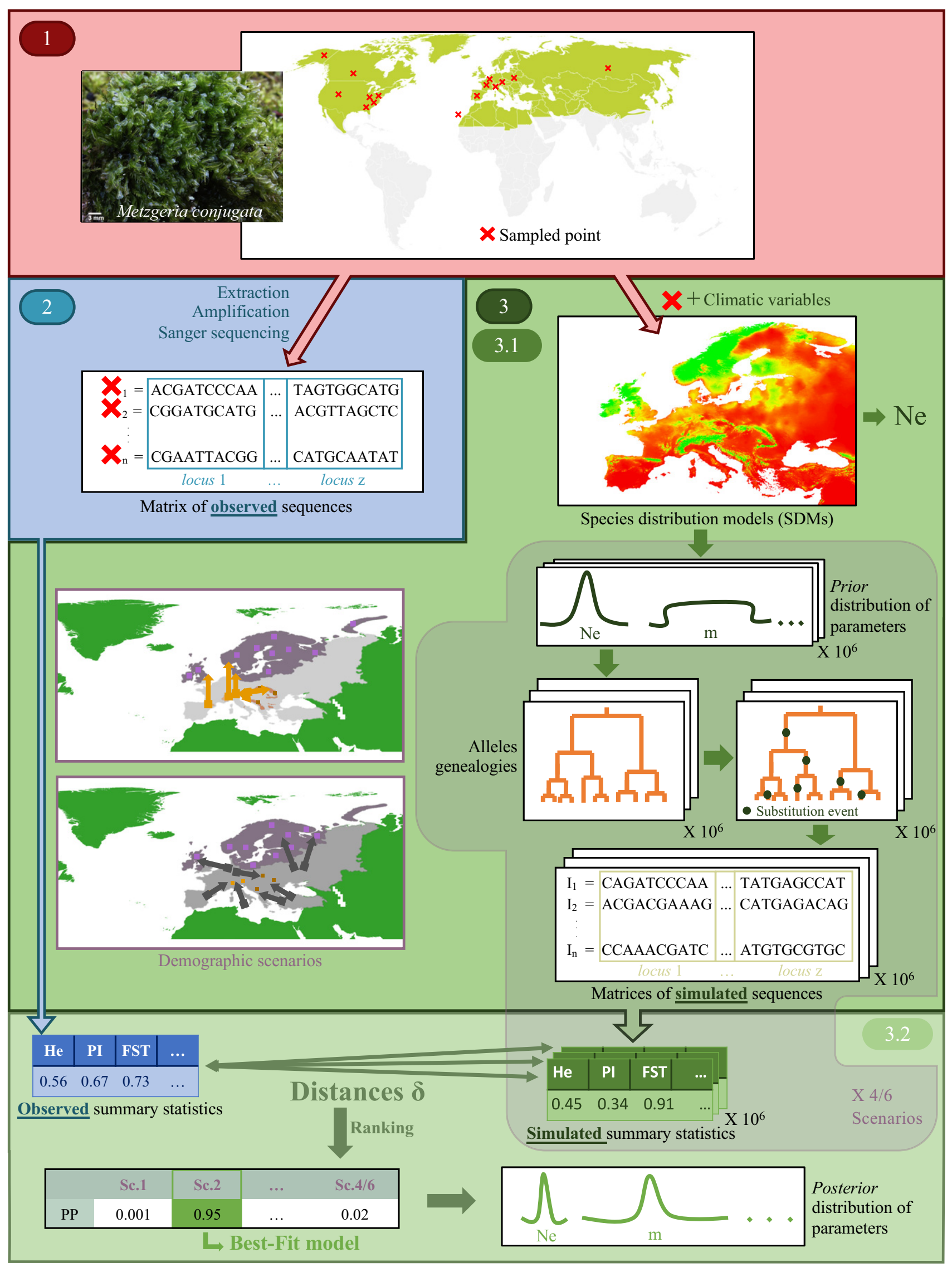




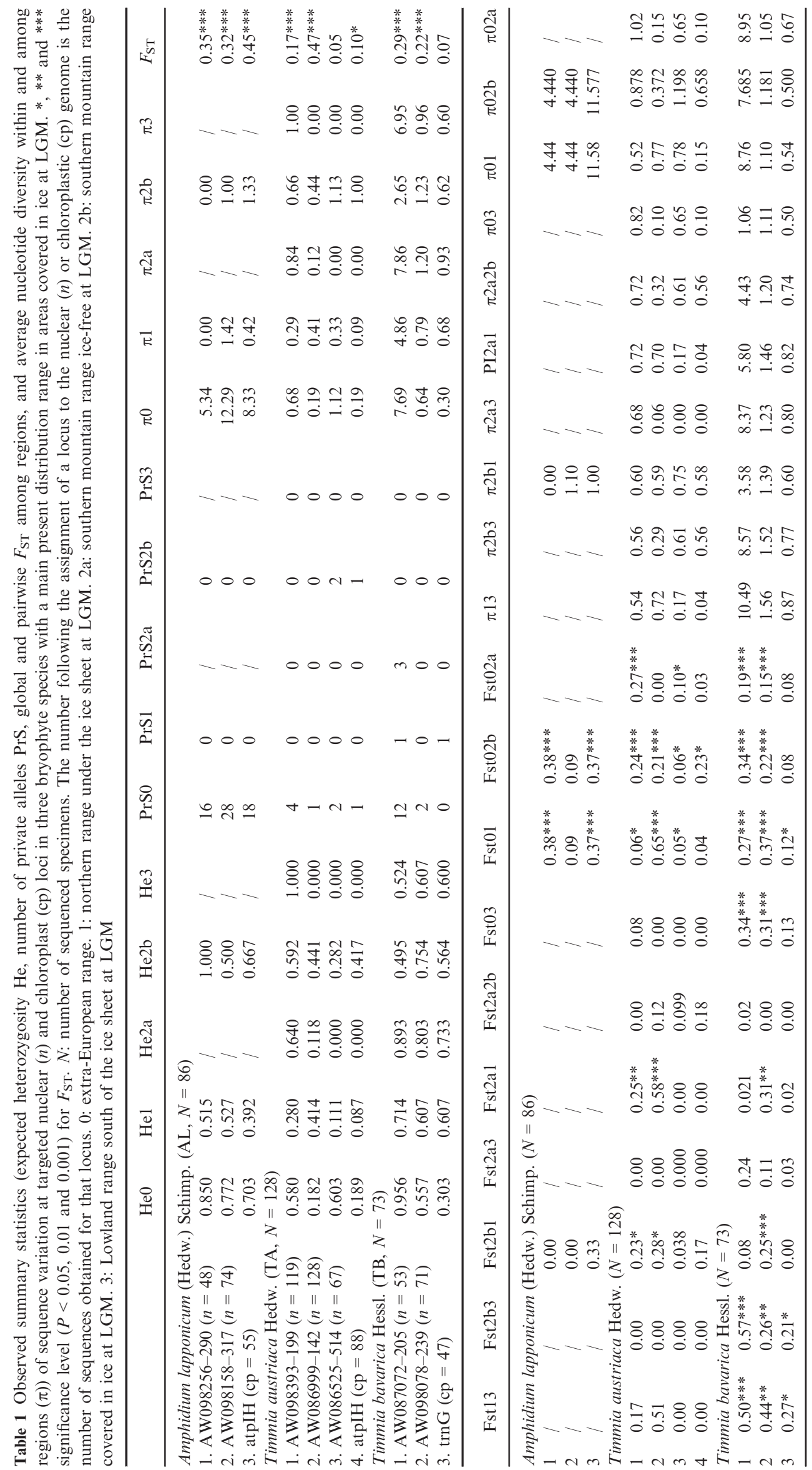




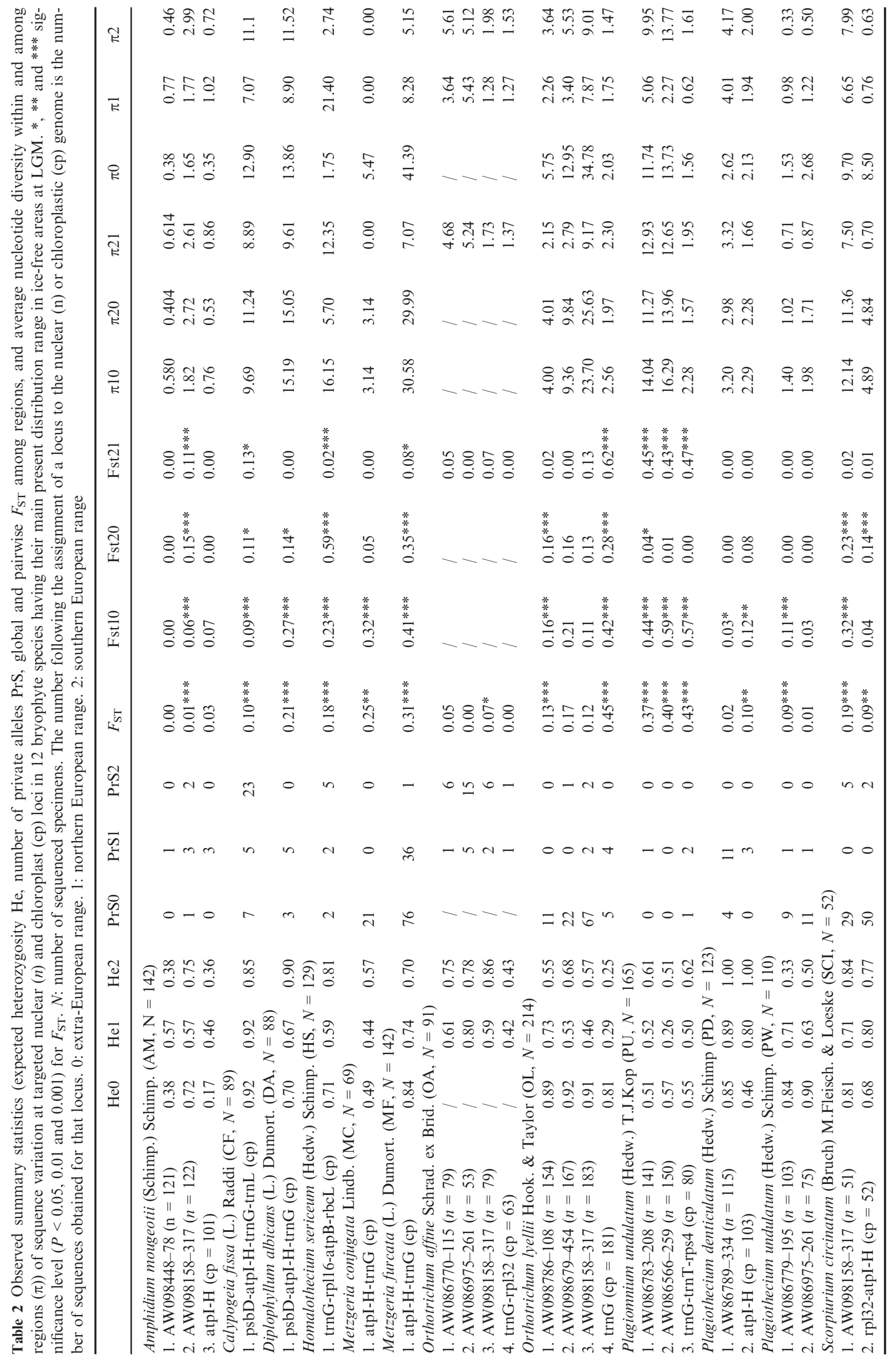



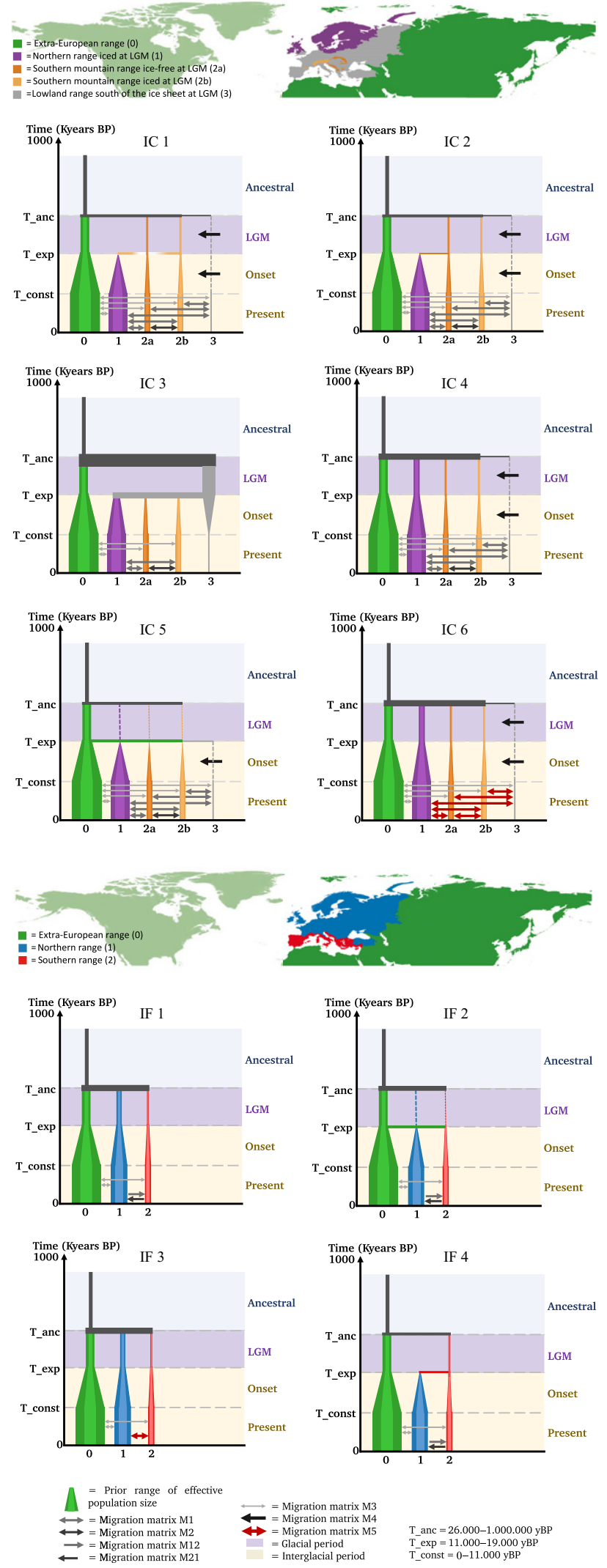

T_anc $=26.000-1.000 .000$ yBP
T $\exp =11.000-19.000$ yBP T-exp $11.000-190.000 \mathrm{yBP}$

concatenated and considered as one locus due to the linkage of chloroplastic genes, whereas each nuclear locus was considered individually.
Figure 2 Hypothetical demographical scenarios for the post-glacial recolonisation of Europe since the Last Glacial Maximum in species with their present main distribution range in areas that were covered in ice and ice-free at LGM (scenarios IC and IF respectively). Arrows represent migration rates among regions. ICl: Southern mountain range refugia iced at LGM. IC2: Southern mountain range refugia ice-free at LGM. IC3: Lowland refugia south of the ice sheet at LGM. IC4: micro-refugia within the northern ice sheet and the southern mountain ranges. IC5: extra-European post-glacial recolonisation. IC6: no genetic structure due to intense post-glacial migrations. IF1: northern micro-refugia. IF2: extraEuropean post-glacial recolonisation. IF3: no genetic structure due to intense post-glacial migrations. IF4: southern refugia.

\section{Statistical analyses}

Characterising population structure and genetic diversity

Haplotype networks were computed for each species and locus to visualise the geographic partitioning of genetic variation and describe relationships among alleles from different regions with PEGAS (Paradis 2010). To characterise the genetic structure and diversity of each biogeographical region, the following summary statistics were computed with ARLSUMSTAT 3.5.2.2 (Excoffier \& Lischer 2010) for each locus and species: expected heterozygosity $(\mathrm{He})$, nucleotide diversity $(\pi)$ and number of private polymorphic sites $(\mathrm{PrS})$, global $F_{\mathrm{ST}}, F_{\mathrm{ST}}$ and nucleotide diversity $(\pi)$ between pairs of regions. In addition, we tested the hypothesis that the global $F_{\mathrm{ST}}$ was significantly different from 0 by randomly permuting specimens among regions 1000 times. Variation in summary statistics among species was described by a principal component analysis (PCA).

\section{Design of the demographic scenarios}

We determined whether sequence variation at each locus was compatible with competing historical demographic scenarios designed for IF and IC species, respectively, by implementing an $\mathrm{ABC}$ analysis (Lintusaari et al. 2017). Briefly, millions of allele genealogies are generated from coalescent simulations sampling a range of demographic parameters (effective population size $\mathrm{Ne}$, migration rates). These genealogies are then used to map substitutions and generate simulated DNA alignments of the same size as the observed data. The simulations that exhibit the closest resemblance with the observed data are then selected to identify the demographic scenarios and their parameters that are the most likely to have generated the observed data (Fig. 1).

Our demographic scenarios involved four time slices (Fig. 2). The first time slice ranged between the final coalescence event and $T_{-}$anc, at which all populations are merged, and at which $\mathrm{Ne}$ of the resulting population is divided by 1000 to allow the final coalescence of all remaining alleles. T_anc was sampled from a uniform distribution between $10^{6}$ and 26000 years BP. The second time slice ranged between T_anc and T_exp, which marks the beginning of the post-glacial expansion and was sampled from a uniform distribution between 19000 and 11000 years BP. During this second period, which encompasses the LGM, between 26000 and 19000 years BP, population sizes were constant. The third time slice corresponded to the post-glacial expansion, starting at $T_{-}$exp and ending at $T_{-}$const. The fourth time slice marked 
the end of the expansion period, starting at T_const, which was sampled from a uniform distribution between 11000 0 years BP, and ending at time present. During this period, $\mathrm{Ne}$ remained stable and migrations among all regions are allowed. This framework allowed to consider a large range of demographic scenarios, from extremely rapid expansions followed by stasis ( $T_{-}$exp and $T_{-}$const both sampled at 11000 years BP) to progressive and continuous expansion since the end of the LGM (T_exp sampled at 19000 years BP, T_const sampled at time present).

For IF species, specific asymmetric migration rates described the movement of alleles between the southern and northern ranges (migration matrices M12 and M21, Fig. 2). For IC species, symmetric migrations were allowed between each European region (migration matrix M1, Fig. 2). A specific symmetric migration matrix (M2, Fig. 2) was implemented between the southern mountain ranges during the fourth time slice to allow these two populations to form a large, panmictic population. We controlled for migrations between the extraEuropean range and each of the European regions for all scenarios (symmetric migration matrix M3, Fig. 2).

For IC species, six demographic scenarios were designed (Fig. 2). In the southern mountain range refugium scenarios, populations from the northern range under the ice sheet at LGM originated at T_exp from refugia located in the southern glaciated (scenario IC1) or ice-free (scenario IC2) mountain ranges at LGM. The extant lowland population is considered to result from a recent founding event. To simulate this, all alleles in this lowland population were transferred into the northern areas and the southern mountain ranges by implementing a high migration rate (asymmetric migration matrix M4, Fig. 2) from T_const to T_anc. In scenario IC3, populations of the northern areas and the southern mountain ranges originated at T_exp from the lowland population. In this scenario, the latter represents the relicts of a large ancestral population at LGM. Populations of the northern areas and the southern mountain ranges underwent an expansion, whereas the lowland population underwent a bottleneck from T_exp to T_const. In scenario IC4, populations of the northern areas and the southern mountain ranges are the relicts of persisting populations in local micro-refugia since the LGM. Like in scenario IC1 and IC2, the lowland population is considered to result from a recent founding event from either the northern areas or the southern mountain ranges. Scenario IC5 involves that, although small populations might have persisted in Europe, the post-glacial recolonisation mainly took place from migrants of extra-European origin at T_exp, taking advantage of the empty niche space left in Europe after the LGM. We allowed a range ('Contri'), sampled from a uniform distribution between 80 and $100 \%$, of individuals of extra-European origin, while the remaining $0-20 \%$ of individuals corresponded to relictual populations that persisted in Europe during the LGM. Like in scenarios IC1, IC2 and IC4, the population from the lowland areas was considered to result from a recent founding event from the northern areas or the southern mountain ranges. Finally, scenario IC6 represents our null hypothesis, according to which there is no significant genetic structure $\left(F_{\mathrm{ST}}=0\right)$ due to high dispersal rates among European regions (migration matrix M5, Fig. 2) from T_const to time present.
For IF species, the northern refugium scenario (IF1) proposes that northern populations survived in situ in micro-refugia during LGM and were involved in the post-glacial recolonisation of northern Europe. Scenarios IF2 and IF3 describe an extra-European origin of the post-glacial recolonisation of Europe at T_exp and the absence of any spatial genetic structure, respectively, and their design is thus identical to the one of scenarios IC5 and IC6. In the southern refugium scenario (IF4), the post-glacial recolonisation of the southern range took place from Mediterranean refugia at T_exp.

\section{Estimation and prior distributions of model parameters}

We sampled uniform prior distributions conservatively bounded by the slowest and fastest rates observed across a range of species and loci in previous studies (Patiño et al. 2015; Désamoré et al. 2016). These prior distributions, which ranged between $10^{-7}$ and $10^{-4}$ substitutions/site/myr, were sampled independently, allowing for different posterior probability distributions to characterise the substitution rates of each locus.

Migration rates (matrices M1, M12, M21, M2 and M3) were independently sampled from a uniform distribution ranging between 0 and $10 \%$ of migrants per population per generation (Patiño et al. 2015; Désamoré et al. 2016) but, based on Désamoré et al. (2016), we enforced a rule according to which the intercontinental migration rate (M3) was lower than the migration rate within Europe (M1, M12, M21 and M2). The matrices describing high migration rates (matrices M4 and M5) were set at 0.2 .

We used information on life strategies to determine the age at sexual maturity defining the generation time. All the species investigated in the present study are perennial and start producing sporophytes from about 10 years (During 1992). All bryophyte species are, however, capable of clonal reproduction, which may take place from the earliest developmental stages. Therefore, we set the generation time at 5 years, which represents a compromise between early asexual reproduction and delayed sexual reproduction. The generation time was fixed instead of sampled from a prior distribution because uncertainty in the time estimates was taken into account by allowing a range, instead of a fixed value, for the time periods defined (T_const, T_exp and T_anc). The fact that the mode of the posterior distributions of those parameters was either centred or shifted towards the highest or lowest values of the prior range (Fig. S2) suggests that our estimate of the generation time is realistic, as an over- or underestimation of it would lead to posterior distributions of those parameters that would consistently increase or decrease towards the boundaries of the prior distribution.

The present $\mathrm{Ne}$ values were sampled from uniform prior distributions that were defined for each species (Table S2a,b), except for the lowland population in scenarios IC1-6, which was associated with a uniform prior ranging between 1 and 50 individuals. These prior distributions were derived using species distribution models to predict the number of macroclimatically suitable pixels of $5 \mathrm{~km}^{2}$. This number was subsequently multiplied by the expected value of Ne per pixel from Patiño et al. (2015) and Désamoré et al. (2016) (see 
Appendix S1 for details). The fact that the mode of the posterior probability distributions of $\mathrm{Ne}$ for all regions and species (Fig. S2) was comprised within the boundaries of the prior distributions confirms that the priors that we employed were realistic. To simulate the large ancestral lowland population in scenario IC3, a uniform prior distribution was set for its LGM Ne, whose range was defined using species distribution models projected on LGM climatic variables.

To simulate bottlenecks, we constrained Ne at LGM to be a portion of $\mathrm{Ne}$ at time present by multiplying the latter by a factor $R$ sampled from a uniform prior distribution ranging from 0.0001 to 0.01 . To simulate the founding effect experienced by extra-European migrants at T_exp in scenarios IC5 and IF3, we sampled $R$ in Europe from a uniform distribution ranging between 0.005 and 0.0005 , and we further implemented a rule according to which the size of the European population was always at least 10 times lower than that of the extra-European one. To simulate the founding effect experienced by migrants during the colonisation of the northern range at T_exp in scenarios IF4, IC1 and IC2, respectively, $\mathrm{Ne}$ of these populations at T_exp was sampled from a uniform distribution ranging between 2 and 100 . We further implemented a rule according to which $\mathrm{Ne}$ of these populations was at least ten times lower than the size of the populations of the southern (scenario IF4) or the southern mountain ranges (scenarios IC1-2).

\section{$A B C$ analyses and model selection}

Approximate Bayesian computation analyses were conducted using ABCtoolbox2.0 (Wegmann et al. 2010) in combination with fastsimcoal2 (Excoffier et al. 2013). For each species and scenario, $10^{6}$ coalescent simulations were conducted. In each simulation, parameter values were randomly sampled from prior distributions described above. The nucleotide substitution model used to simulate the sequence data from each tree and for each locus was a Kimura 2-parameter with a transition-transversion ratio set at 0.33 . Each analysis resulted in $10^{6}$ simulated sequence data sets identical in size (i.e. number and length of sequences) to the corresponding observed data set.

We computed the summary statistics listed above for all simulated data. Highly correlated statistics (correlation coefficient $>95 \%$ ) were removed. Euclidean distances were calculated between the normalised observed and simulated summary statistics. For each scenario and species, we retained the best 1000 simulations (i.e. those with the smallest Euclidean distance between the simulated and observed summary statistics). A post-sampling regression adjustment (ABCGLM) was finally performed to derive the posterior probability distributions of each scenario and model parameters (Leuenberger \& Wegmann 2010) from this first selection. The posterior probability distributions were smoothed using the diracPeakWidth parameter, set at 0.01 .

Two model validation procedures were implemented. First, we determined whether the summary statistics of the observed data fell within the range of the simulated summary statistics. We computed the marginal density $P$-value and implemented a PCA of the summary statistics of the observed and 1000 best simulated data of each of the competing demographic scenarios. Second, we measured the proportion of 'false positives' that is the selection of the wrong model during model selection (Robert et al. 2011). We sampled a total of 1000 sets of summary statistics simulated under each demographic scenario. These sets of 'pseudo-observed' data were analysed using the same procedure of model selection as described above to compute the percentage of simulations erroneously assigned to each scenario.

\section{RESULTS}

Network analyses and distribution maps of alleles can be found in Fig. S1. The widespread distribution of many alleles, together with the sharing of alleles among specimens from different biogeographical regions, the close relationships among alleles sampled from different biogeographical regions and the presence of unrelated alleles in individuals from the same biogeographical region, all point to intense migrations among regions.

The comparison of the observed patterns of genetic structure and diversity in the 15 selected species with those expected under competing post-glacial recolonisation scenarios in an $\mathrm{ABC}$ framework in fact points to a complex post-glacial history with a substantial contribution from populations located in their extra-European range. The scenario of a postglacial recolonisation of Europe by extra-European migrants (IF2) had the highest posterior probability in 7 of the 12 IF species investigated, followed by the southern (IF4, 3 species) and northern (IF1, 2 species) refugium scenarios (Fig. 3). The scenario, according to which recent migrations erased any genetic structure (IF3), was never selected. For the three IC species investigated, the scenarios of local micro-refugia (IC4) on the one hand, and of recolonisation from lowland areas located south of the ice sheet at LGM (IC3) on the other hand, were selected for two and one of the species respectively (Fig. 3).

The examination of the posterior probability distributions of the demographic parameters (Fig. S2) reveals that, for the species that conform to a recolonisation of Europe from allochthonous origin, the distribution of the proportion of migrants of allochthonous origin at the beginning of the expansion (parameter 'Contri' in Fig. S2) peaks at the highest values of the prior range (i.e. 95-100\%), except in Plagiothecium undulatum. In the three investigated IC species, the mode of the posterior distribution of the ongoing migration rate between Europe and extra-European regions is shifted towards the right of the mode of the prior distribution, at values of $2-4 \%$ of migrants per generation.

The posterior distribution of the timing of the beginning of the post-glacial expansion (T_exp, Fig. S2) consistently peaked at the lowest values of the prior distribution (approximately around 11 000-12 000 years BP), pointing to a delay of the post-glacial expansion, which did not occur directly at the end of the LGM, around 19000 years BP. In five out of the seven species that conformed to the scenario of post-glacial recolonisation of extra-European origin, the distribution of the timing of the end of the expansion (T_const, Fig. S2) peaked at the highest values of the prior range (around 10 000-11000 years BP). This timing indicates that, for 
(a)

\section{Species with a main present distribution range in} areas covered in ice at LGM

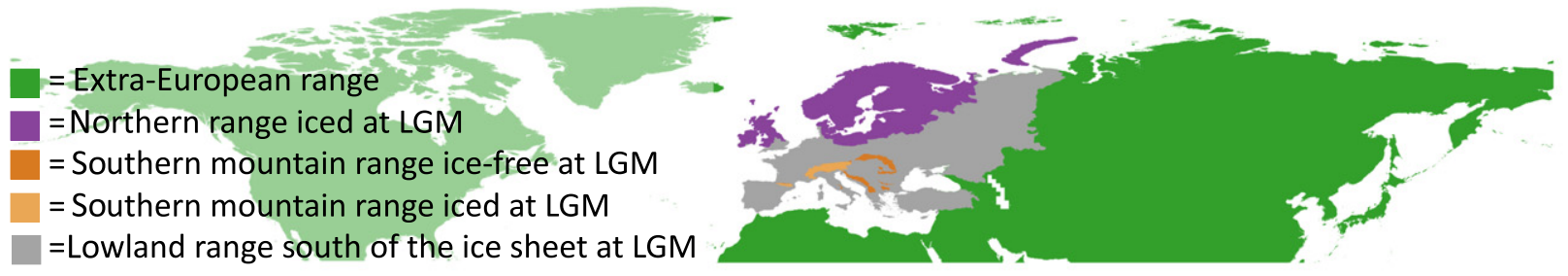

IC 1: iced southern mountain range refugia

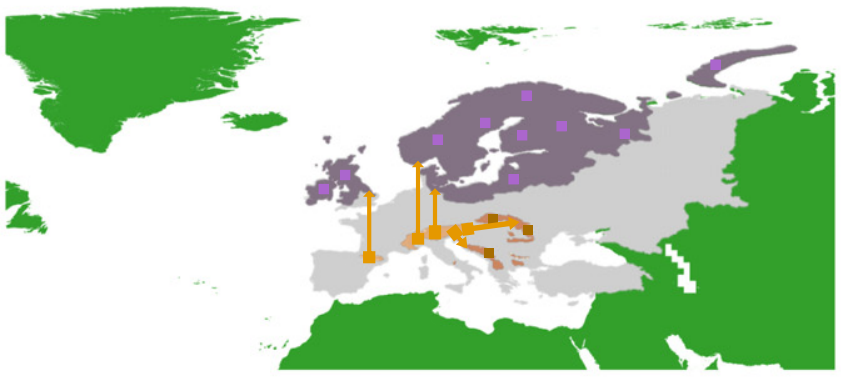

IC 3: lowland refugia

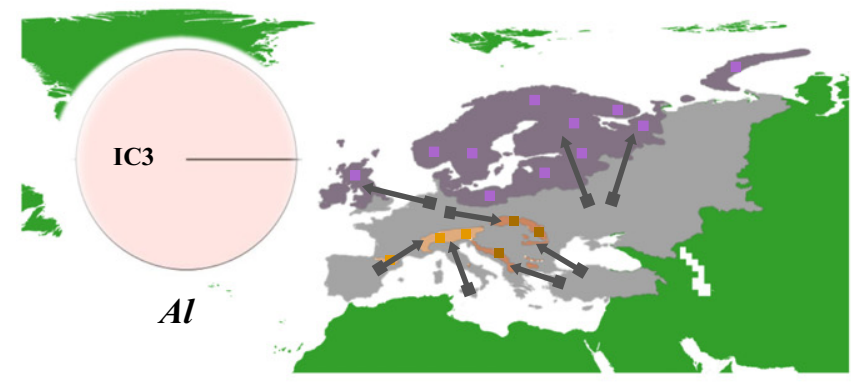

IC 5: extra-European postglacial recolonisation

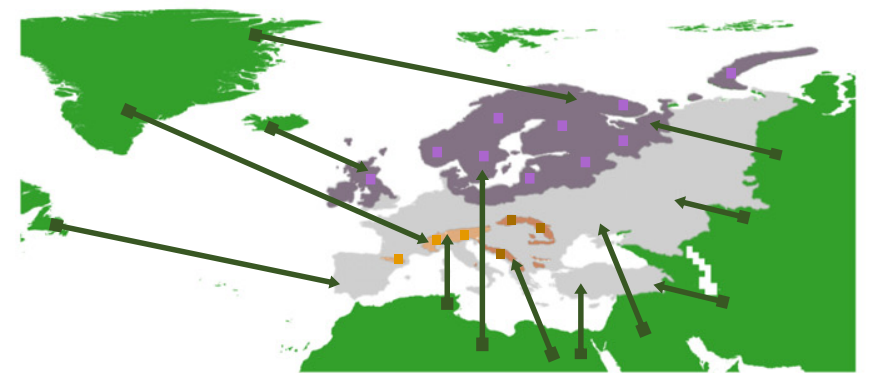

IC 2: ice-free southern mountain range refugia

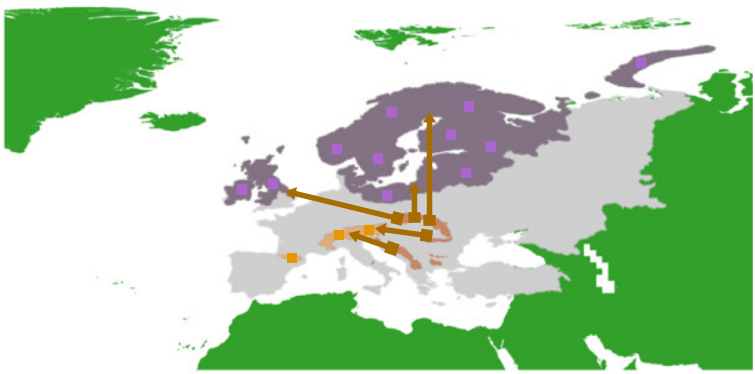

IC 4: micro-refugia

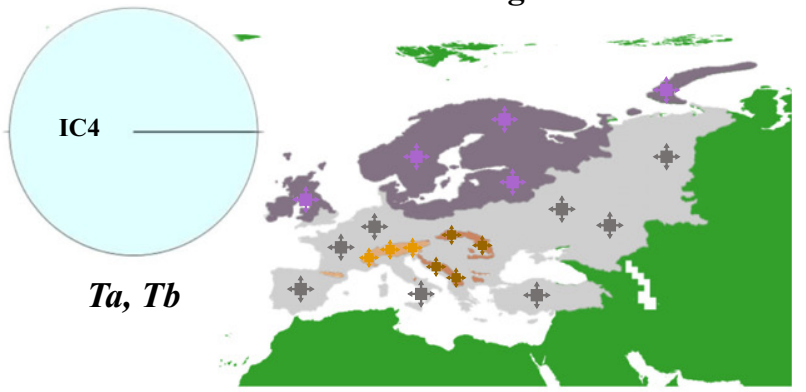

IC 6: lack of spatial genetic structure due to dispersal

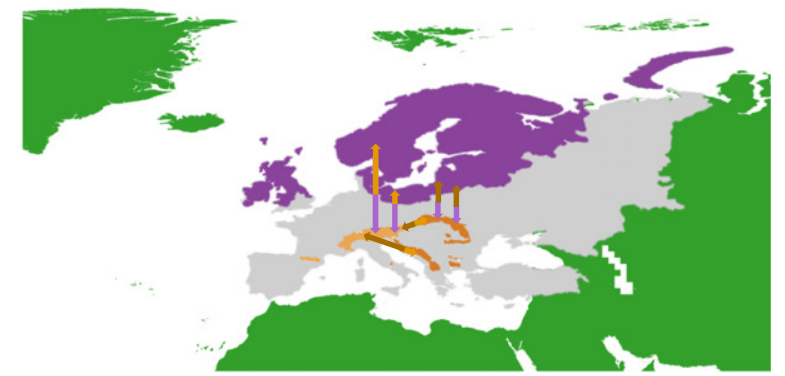

= Migration among regions

$$
\text { = Local expansion from a micro-refugium }
$$

Figure 3 Support for competing post-glacial demographic scenarios in bryophyte species with their present main distribution range in areas that were covered in ice (a) and ice-free (b) at LGM (scenarios IC and IF, respectively) inferred by ABC model selection. Pie diagrams reflect the posterior probabilities of each scenario. Arrows represent migrations and squares represent hypothetical micro-refugia. Al: Amphidium lapponicum; Am: Amphidium mougeotii; Cf: Calypogeia fissa; Da: Diplophyllum albicans; Hs: Homalothecium sericeum; Mc: Metzgeria conjugata; Mf: Metzgeria furcata; Oa: Orthotrichum affine; Ol: Orthotrichum lyellii; Pd: Plagiothecium denticulatum; Pw: Plagiothecium undulatum; Pu: Plagiomnium undulatum; Sci: Scorpiurium circinatum; Ta: Timmia autriaca; Tb: Timmia bavarica. 
(b)

\section{Species with a main present distribution range in ice-free areas at LGM}

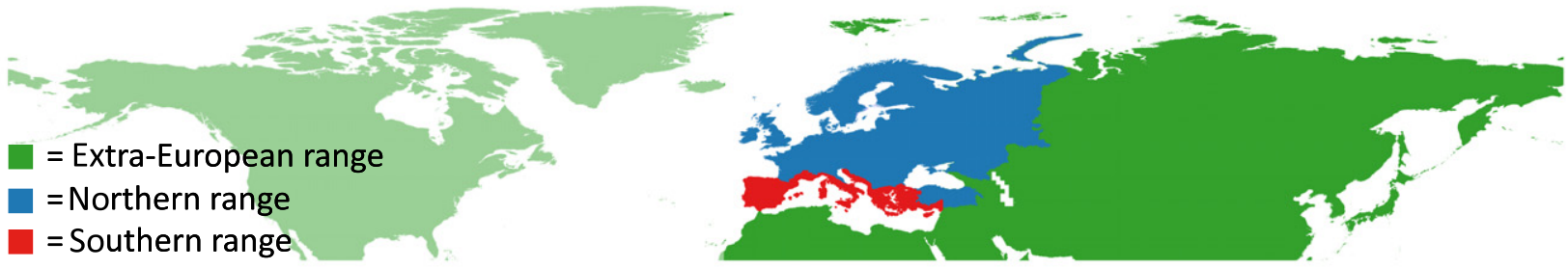

IF 2: extra-European post-glacial recolonisation

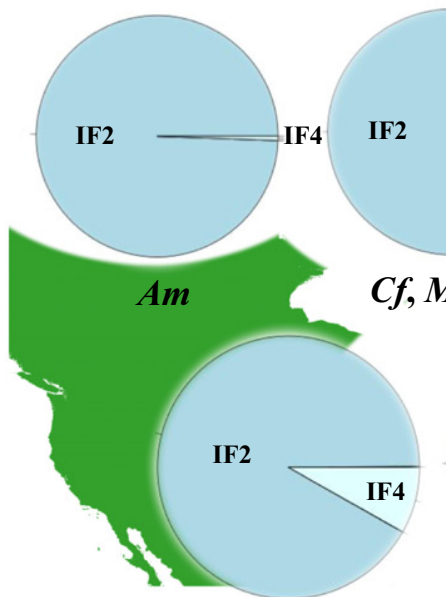

$P d$
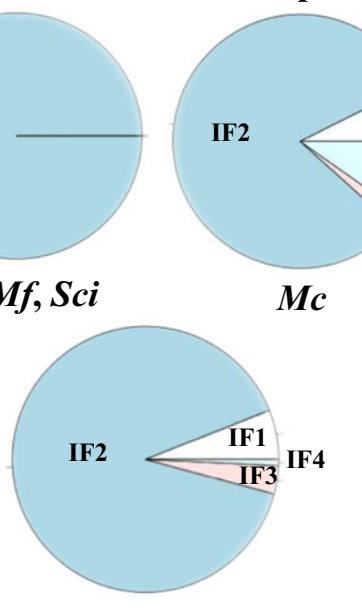

$P w$

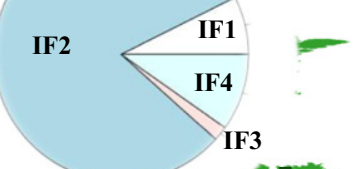

- - -

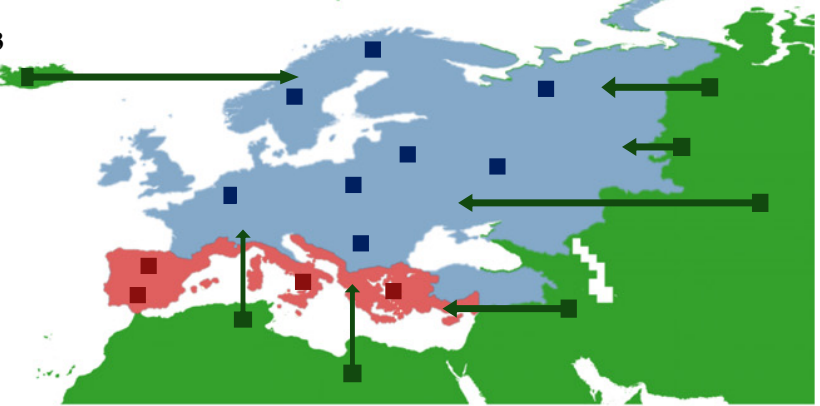

IF 4: southern refugia

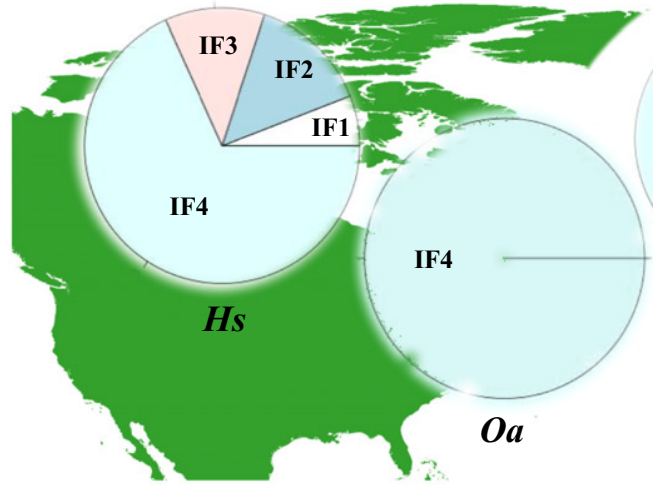

IF 1: northern refugia

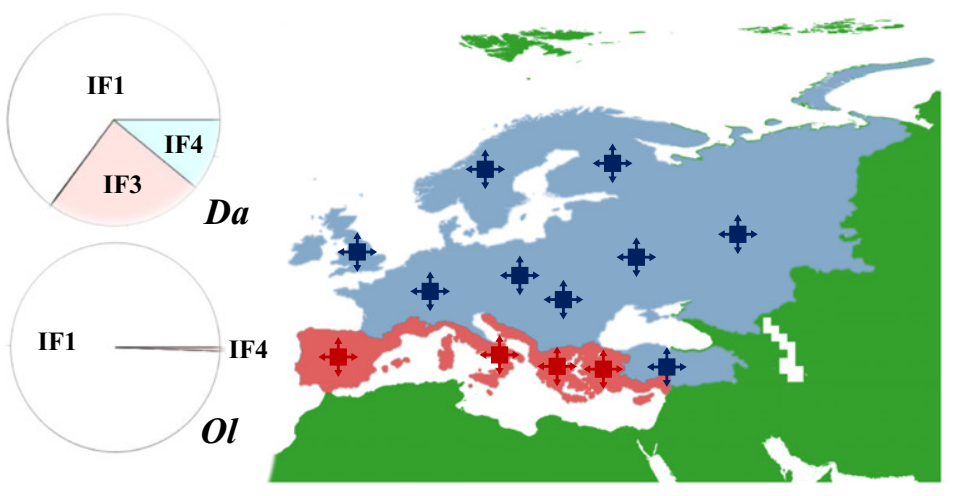

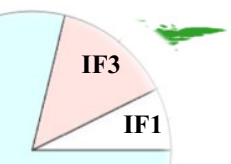

IF4

$\mathrm{Pu}$

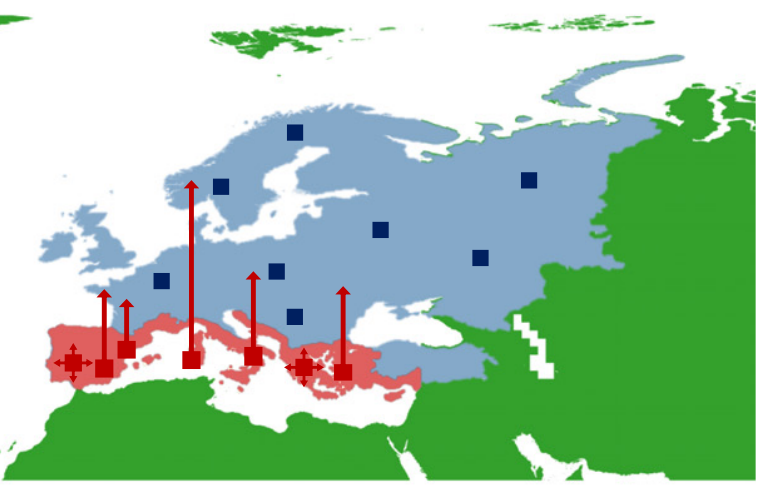

IF 3: lack of spatial genetic structure due to dispersal

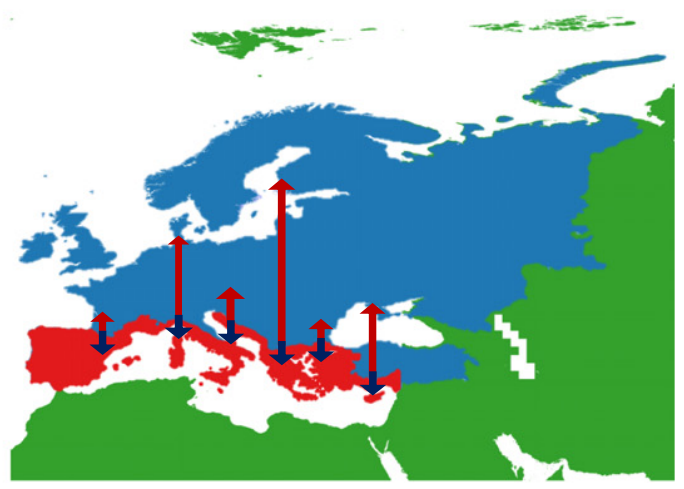

Figure 3 continued 
these species, the post-glacial expansion was limited in time and followed by a long (about 10000 years) period of stable population size until present time. In all the other species, the posterior distribution of the end of the post-glacial expansion peaked at the lowest values of the prior range (around time present), pointing to either a progressive expansion that ceased recently or is still underway, or to a very limited period of migrations among regions (since in all scenarios, migration among regions was permitted only after population expansion). The posterior probability distributions of migration rates between northern and southern areas in Europe after the expansion period consistently peaked at the lowest values of the prior range, pointing to the latter hypothesis.

A summary of the model validation procedures is presented in Table S3. The simulated data laid within the range of the observed data that is the values of the summary statistics computed from the observed data were included within the variation of those derived from the 1000 best simulations for each demographic scenario, as revealed on the first two axes of a PCA (Fig. S3a, b). In addition, the marginal density $P$-values of the best-fit models were higher than 0.05 in 10 out of the 15 species investigated, leading to the acceptance of the null hypothesis that the simulated data are compatible with the observed data. The percentage of false positives during model selection was generally low, except for an obvious bias in the case of the northern micro-refugium scenario. The rate of false positive for the latter in Diplophyllum albicans and Orthotrichum lyellii suggests that patterns of genetic variation in these two species are compatible with different scenarios, strongly weakening the confidence for model selection in this case.

The observed population structure and genetic diversity summary statistics are displayed per species and per locus in Tables 1 and 2. The PCA of these statistics shows that species assigned to the same historical scenario of post-glacial recolonisation tend to exhibit similar genetic characteristics that differentiate them from species assigned to different scenarios (Fig. 4a). Thus, species assigned to the scenario of post-glacial recolonisation from extra-European origin, which occupy the upper right portion of the two first PCA axes, tend to exhibit lower global $F_{\mathrm{ST}}$ (Fig. $4 \mathrm{~b} 1$ ), lower pairwise $F_{\mathrm{ST}}$ values (Fig. 4b2), and more similar genetic diversities (Table 2) between the southern and northern ranges than species assigned to other scenarios. Species assigned to the southern refugium scenario, which have negative coordinates along PCA2, exhibit high nucleotide diversities in the southern range, while species assigned to the northern refugium (a)

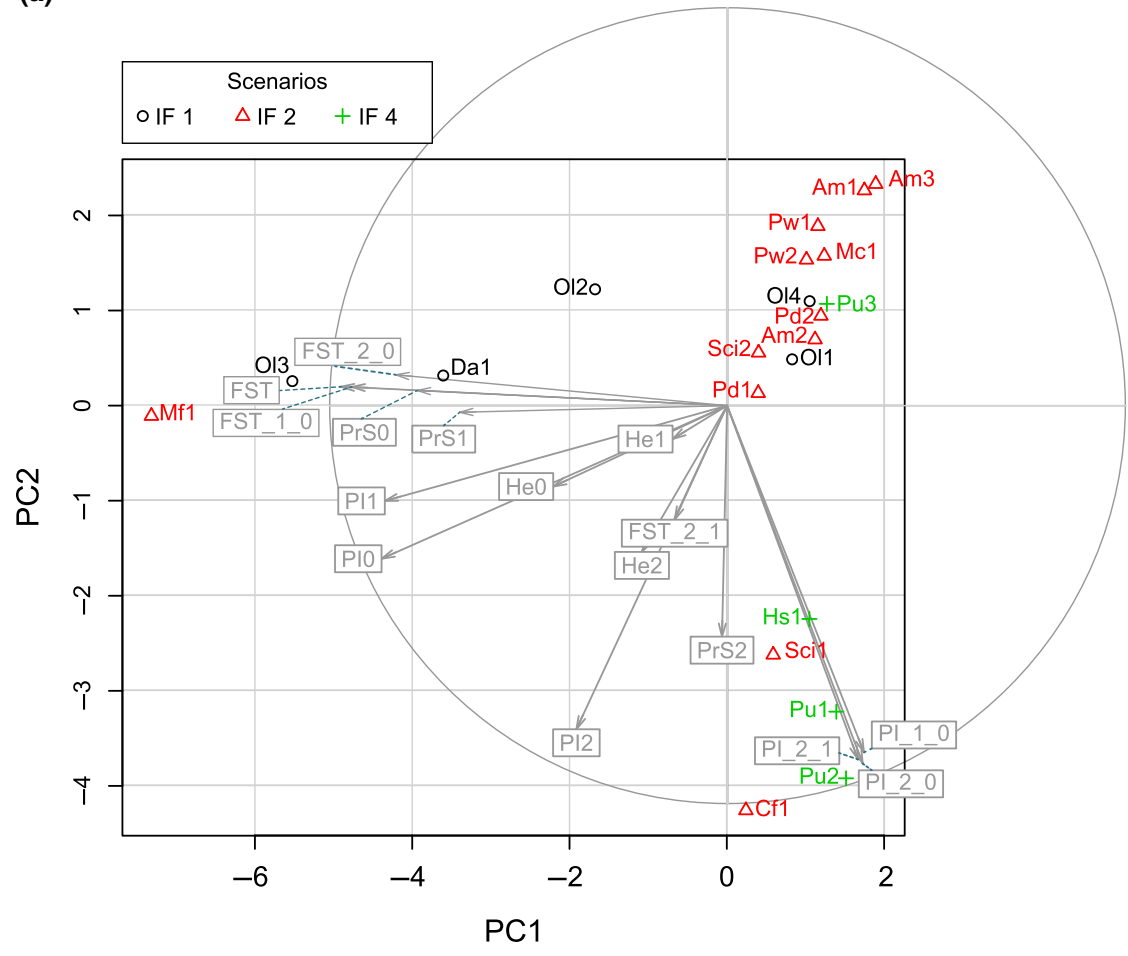

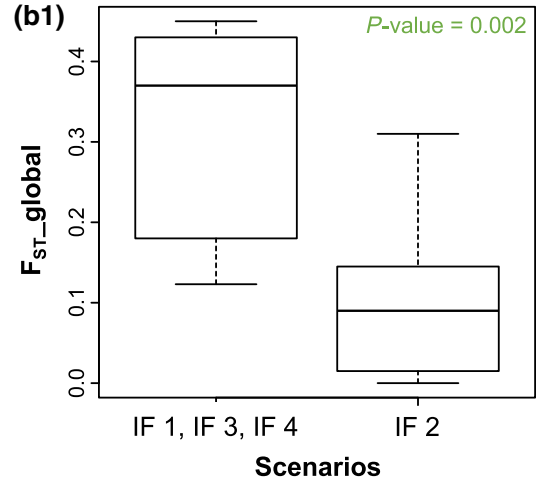

(b2)

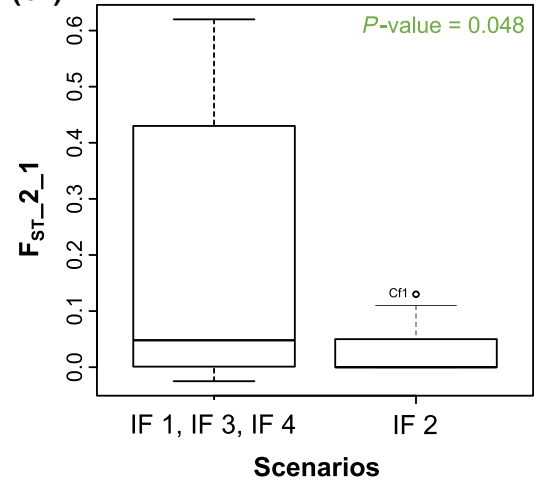

Figure 4 (a) Principal component analysis of the summary statistics characterising population structure and genetic diversity (expected heterozygosity He, nucleotide diversity $\pi$ and number of private polymorphic sites PrS per region, global $F_{\mathrm{ST}}, F_{\mathrm{ST}}$ and $\pi$ between each pair of regions) per locus (see Table 2 for locus numbers) and region (0: extra-European range; 1: northern European range; 2: southern European range) in selected bryophyte species with their core present distribution in ice-free areas at LGM (see Table 2 for labels). Arrow lengths are proportional to the correlation coefficient of the corresponding summary statistic and the axes. Colours correspond to the assignment of each species to the scenario of post-glacial recolonisation of Europe (see Fig. 3), as selected by the ABC-GLM procedure. (b) Box plots and $P$-values of $t$-test comparisons of selected summary statistics whose relevance is highlighted by the PCA between species assigned to a scenario of allochthonous (IF2) or autochthonous (IF1, 3-4) post-glacial recolonisation of Europe respectively. (1) global $F_{\mathrm{ST}}$. (2) $F_{\mathrm{ST}}$ between northern and southern Europe (2). 
scenario exhibit high nucleotide diversities and high numbers of private segregating sites in northern areas.

\section{DISCUSSION}

Patterns of post-glacial recolonisation in European bryophytes are not consistent with the idea that the intensity of migrations erased any genetic structure. The diversity of scenarios involved highlights a complex post-glacial history of European bryophytes from multiple sources. This complexity contrasts with the prevailing model in which species that have their present distribution mainly in areas that were ice-free at LGM migrated northwards from southern refugia (Hewitt 2000; Petit et al. 2003). The validity of this historical demographic model has been recently challenged for North American trees (Lumibao et al. 2017). Our findings thus further challenge the taxonomic generality of the southern refugium scenario that has long been assumed to explain the distribution of genetic variation in bryophytes based on single-species analyses (Cronberg 2000; Grundmann et al. 2008).

The dominant scenario of post-glacial recolonisation of Europe by bryophyte species that are mainly distributed today in areas that were ice-free at LGM involved a major contribution of migrants of allochthonous origin. The globally balanced genetic diversities and extremely low divergence observed between southern and northern regions are fully consistent with such a scenario, in contrast to the gradual decrease in genetic diversity towards the north observed in seed plants (Petit et al. 2003).

Previous evidence in angiosperms demonstrated the post-glacial recolonisation of a remote Arctic archipelago from distant sources (Alsos et al. 2007). Individual instances of extra-European refugia (Hutsemékers et al. 2011; Laenen et al. 2011; Stenøien et al. 2011) and a de novo colonisation of oceanic areas from Macaronesian ancestors (Patiño et al. 2015) were further evidenced during the post-glacial history of European bryophytes. The present study is, however, the first to demonstrate and quantify, from a small but independent sample of 12 species that have their main present distribution ranges in ice-free areas at LGM, the substantial contribution of allochthonous migrants in the post-glacial assembly of European bryophyte floras, which is unparalleled in other plants and animals.

Although there was a slight shift of the mode of the posterior probability distribution towards high values of the migration rate between the European and extra-European range in species having their core present distribution range in iced areas at LGM, which is fully compatible with the substantial contribution of extra-European migrants in species distributed in ice-free areas at LGM, Amphidium lapponicum, Timmia austriaca and Timmia bavarica exhibited a strikingly different pattern of in situ persistence at their current locations, some of which were fully glaciated at LGM. Such a scenario is fully compatible with the reported ability of some species to remain viable after more than 1000 years in ice (La Farge et al. 2013; Roads et al. 2014).

The difference in the main origins of species that are currently distributed in areas that were ice-free and covered in ice at LGM is puzzling. This difference cannot, at first sight, be interpreted in terms of life-history traits. In Amphidium, for example, A. lapponicum produces large numbers of capsules with small spores, but recolonised Europe from autochthonous populations, whereas in A. mougeotii, which seldom produces sporophytes and does not produce specialised asexual diaspores, recolonisation took mostly place from allochthonous migrants.

Projections of the species distribution models calibrated under present climatic conditions onto LGM climatic layers (Fig. S4) predict that, with the exception of a few species (Scorpiurium circinatum and, to a lesser extent, $D$. albicans and $P$. undulatum), southern Europe and the southern range of northern Europe were extensively climatically favourable at LGM, pointing to the potential existence of sufficiently large refugia within Europe. Palaeontological evidence indicates, however, that the full-glacial landscape of Eurasia was largely treeless, with a dominance of steppe and other tundra types of vegetation, suggesting that palaeoclimatic reconstructions, on which our species distribution models are built, predicted a warmer and moister climate than it probably was (Tzedakis et al. 2013; Binney et al. 2017). Therefore, the limited contribution of the northern micro-refugium scenario, which contrasts with our primary expectations, and of the southern refugium scenario to explain the post-glacial history of the investigated species may be due to the fact that European refugia have been too small and too scattered as compared to the substantial waves of extra-European origin to actually contribute to the post-glacial recolonisation of the continent. As Semerikov et al. (2013) in fact suggested, it should not be firmly concluded that putative refugial populations necessarily contributed extensively to local modern populations, as the spread of new individuals from adjacent regions would have occurred over several millennia as climates changed (Binney et al. 2017).

A consistent signal for a delay in the post-glacial recolonisation of Europe since the end of the LGM (19 000 years BP) was evidenced across all investigated species by the shift of the posterior probability distribution marking the beginning of the expansion phase towards recent periods. Such a delay could be interpreted in terms of either unsuitable conditions at the beginning of the current interglacial period, and/or a delay in the recolonisation of suitable habitats. The critical transition from predominantly glacial to largely interglacial, moister climates inferred from major changes in fossil pollen records 14000 years BP (Pearson 2006) supports the former hypothesis. A delay in the recolonisation of suitable habitats is, conversely, not supported by the match between the predicted and observed northern limit of distribution in the bryophyte species investigated here (Fig. S5), which contrasts with the absence of many angiosperm species in the North of their potential distribution area (Svenning et al. 2008; Normand et al. 2011). Striking range shifts have already been documented throughout Europe in bryophytes during the past decades (Bosanquet 2012), promoting the idea that major modifications are to be expected in the European bryophyte flora under ongoing climate change.

\section{ACKNOWLEDGEMENTS}

$\mathrm{AL}, \mathrm{AD}, \mathrm{BL}$ and $\mathrm{AV}$ acknowledge financial support from the Belgian Funds for Scientific Research (F.R.S.-FNRS). J.P. was 
funded by the Spanish 'Ministerio de Economía y Competitividad' through the Juan de la Cierva Program - Incorporation (IJCI-2014-19691) and Ramón y Cajal Program (RYC-201620506), and Marie Sklodowska-Curie COFUND, Researchers' Night and Individual Fellowships Global (grant 747238). BL and AD acknowledge financial support from SYNTHESYS (ES-TAF, GB-TAF, NL-TAF) and WBI (Wallonie-Bruxelles International). SFM was supported by funds from the University of Florida. Computational resources were provided by the Consortium des Équipements de Calcul Intensif funded by F.R.S.-FNRS (Grant 2.5020.11). Many thanks are due to three referees and the editor for their constructive comments on the manuscript, and the curators of AZU, BBSUK, BP, BR, CBFS, CR, E, DUKE, FCO, L, MA, MO, MW, NY, O, S, SIENA, TFC, TUR, UPS, and M. Philippe, P. Gorski and T.L. Blockeel for the loan of specimens.

\section{AUTHORSHIP}

$\mathrm{AD}, \mathrm{BL}$ and $\mathrm{AV}$ conceived the project. $\mathrm{AD}$ and $\mathrm{BL}$ produced the molecular data. SFM provided lab facilities and protocols for the sequencing of nuclear loci. AV produced the distribution data. AL, PM, JP, AD and BL performed the genetic analyses. FZ and AL performed the species distribution models. All the authors contributed to the writing of the manuscript.

\section{DATA ACCESSIBILITY STATEMENT}

DNA sequence data are archived in GenBank. DNA alignment matrices and information on species distributions are available from Figshare Repositories: https://doi.org/10.6084/ $\mathrm{m} 9$.figshare.7381130 and https://doi.org/10.6084/m9.figshare. 7422794.

\section{REFERENCES}

Abbott, R.J. \& Brochmann, C. (2003). History and evolution of the arctic flora: in the footsteps of Eric Hultén. Mol. Ecol., 12, 299-313.

Alsos, I.G., Eidesen, P.B., Ehrich, D., Skrede, I., Westergaard, K., Jacobsen, G.H. et al. (2007). Frequent long-distance plant colonization in the changing Arctic. Science, 316, 1606-1609.

Bhagwat, S.A. \& Willis, K.J. (2008). Species persistence in northerly glacial refugia of Europe: a matter of chance or biogeographical traits? J. Biogeogr., 35, 464-482.

Biersma, E.M., Jackson, J.A., Hyvönen, J., Koskinen, S., Linse, K., Griffiths, H. et al. (2017). Global biogeographic patterns in bipolar moss species. Roy. Soc. Open Sci., 4, 170147.

Biersma, E.M., Jackson, J.A., Stech, M., Griffiths, H., Linse, K. \& Convey, P. (2018). Molecular data suggest long-term in situ Antarctic persistence within Antarctica's most speciose plant genus, Schistidium. Front. Ecol. Evol., 6, 77.

Binney, H., Edwards, M., Macias-Fauria, M., Lozhkin, A., Anderson, P., Kaplan, J.O. et al. (2017). Vegetation of Eurasia from the last glacial maximum to present: key biogeographic patterns. Quat. Sci. Rev., 157, 80-97.

Bosanquet, S. (2012). Vagrant epiphytic mosses in England and Wales. Field Bryol., 107, 3-17.

Cannone, N., Corinti, T., Malfasi, F., Gerola, P., Vianelli, A., Vanetti, I. et al. (2017). Moss survival through in situ cryptobiosis after six centuries of glacier burial. Sci. Rep., 7, 4438.
Cronberg, N. (2000). Genotypic diversity of the epiphytic bryophyte Leucodon sciudoides in formerly glaciated versus nonglaciated parts of Europe. Heredity, 84, 710-720.

Darwin, C. (1859). The Origin of Species. John Murray, London.

Désamoré, A., Patiño, J., Mardulyn, P., Laenen, B., McDaniel, S., Zanatta, F. et al. (2016). High migration rates shape the postglacial history of amphi-Atlantic bryophytes. Mol. Ecol., 25, 5568-5584.

During, H.J. (1992). Ecological classification of bryophytes and lichens. In Bryophytes and Lichens in Changing Environment. (eds Bates, J.W., Farmer, A.M.). Clarendon Press, Oxford, pp. 1-31.

Edgar, R.C. (2004). MUSCLE: a multiple sequence alignment method with reduced time and space complexity. BMC Bioinformatics, 5, 113.

Eidesen, P.B., Ehrich, D., Bakkestuen, V., Alsos, I.G., Gilg, O., Taberlet, P. et al. (2013). Genetic roadmap of the Arctic: plant dispersal highways, traffic barriers and capitals of diversity. New Phytol., 200, 898-910.

Excoffier, L. \& Lischer, H.E.L. (2010). Arlequin suite ver 3.5: a new series of programs to perform population genetics analyses under Linux and Windows. Mol. Ecol. Res., 10, 564-567.

Excoffier, L., Dupanloup, I., Huerta-Sánchez, E., Sousa, V.C. \& Foll, M. (2013). Robust demographic inference from genomic and SNP data. PLoS Genet., 9, e1003905.

Gouy, M., Guindon, S. \& Gascuel, O. (2010). SeaView version 4: a multiplatform graphical user interface for sequence alignment and phylogenetic tree building. Mol. Biol. Evol., 27, 221-224.

Grundmann, M., Ansell, S.W., Russell, S.J., Koch, M.A. \& Vogel, J.C. (2008). Hotspots of diversity in a clonal world - the Mediterranean moss Pleurochaete squarrosa in Central Europe. Mol. Ecol., 17, 825-838.

Hewitt, G.M. (1999). Post-glacial recolonisation of European biota. Biol. J. Linn. Soc., 68, 87-112.

Hewitt, G.M. (2000). The genetic legacy of the Quaternary ice ages. Nature, 405, 907-913.

Hewitt, G.M. (2004). Genetic consequences of climatic oscillations in the quaternary. Phil. Trans. Roy. Soc. B, 359, 183-195.

Hooker, J.D. (1862). Outlines on the distribution of arctic plants. Trans. Linn. Soc. London, 23, 251-348.

Hultén, E. (1937). Outline of the History of Arctic and Boreal Biota During the Quarternary Period. Lehre J. Cramer, New York.

Hutsemékers, V., Shaw, A.J., Szvovenyi, P., Gonzalez-Mancebo, J.M., Muñoz, J. \& Vanderpoorten, A. (2011). Islands are not sinks of biodiversity in spore-producing plants. Proc. Natl Acad. Sci. USA, 108, 18989-18994.

Jakab, G. \& Sümegi, P. (2011). The role of bryophyte paleoecology in quaternary climate reconstructions. In Bryophyte Ecology and Climate Change. (eds Tuba, Z., Slack, N.G., Stark, L.R.). Cambridge University Press, Cambridge, pp. 335-358.

Kyrkjeeide, M.O., Stenøien, H.K., Flatberg, K.I. \& Hassel, K. (2014). Glacial refugia and post-glacial colonization patterns in European bryophytes. Lindbergia, 37, 47-59.

Kyrkjeeide, M.O., Hassel, K., Flatberg, K.I., Shaw, A.J., Brochmann, C. \& Stenøien, H.K. (2016). Long-distance dispersal and barriers shape genetic structure of peatmosses (Sphagnum) across the Northern Hemisphere. J. Biogeogr., 43, 1215-1226.

La Farge, C., Krista, H., Williams, K.H. \& England, J.H. (2013). Regeneration of Little Ice Age bryophytes emerging from a polar glacier with implications of totipotency in extreme environments. Proc. Natl Acad. Sci. USA, 110, 9839-9844.

Laenen, B., Désamoré, A., Devos, N., Shaw, A.J., Carine, M.A., Gonzalez-Mancebo, J.M. et al. (2011). Macaronesia: a source of hidden genetic diversity for post-glacial recolonization of western Europe in the leafy liverwort Radula lindenbergiana. J. Biogeogr., 38, 631-639.

Leuenberger, C. \& Wegmann, D. (2010). Bayesian computation and model selection without likelihoods. Genetics, 184, 243-252.

Lintusaari, J., Gutmann, M.U., Dutta, R., Kaski, S. \& Corander, J. (2017). Fundamentals and recent developments in Approximate Bayesian Computation. Syst. Biol., 66, e66-e82. 
Lumibao, C.Y., Hoban, S.M. \& McLachlan, J. (2017). Ice ages leave genetic diversity 'hotspots' in Europe but not in Eastern North America. Ecol. Lett., 20, 1459-1468.

McDaniel, S.F. \& Shaw, A.J. (2005). Selective sweeps and intercontinental migration in the cosmopolitan moss Ceratodon purpureus (Hedw.). Brid. Mol. Ecol., 14, 1121-1132.

McDaniel, S.F., Baren, M.Jv, Jones, K.S., Payton, A.C. \& Quatrano, R.S. (2013). Estimating the nucleotide diversity in Ceratodon purpureus (Ditrichaceae) from 218 conserved exon-primed, intron-spanning nuclear loci. Appl. Plant Sci., 1, 1200387.

Médail, F. \& Diadema, K. (2009). Glacial refugia influence plant diversity patterns in the Mediterranean Basin. J. Biogeogr., 36, 1333-1345.

Normand, S., Ricklefs, R.E., Skov, F., Bladt, J., Tackenberg, O. \& Svenning, J.C. (2011). Postglacial migration supplements climate in determining plant species ranges in Europe. Proc. R. Soc. Lond. B, 278, 3644-3653.

Paradis, E. (2010). Pegas: an R package for population genetics with an integrated-modular approach. Bioinformatics, 26, 419-420.

Patiño, J., Carine, M., Mardulyn, P., Devos, N., Mateo, R.G., GonzálezMancebo, J.M. et al. (2015). Approximate Bayesian Computation reveals the crucial role of oceanic islands for the assembly of continental biodiversity. Syst. Biol., 64, 579-589.

Pearson, R.G. (2006). Climate change and the migration capacity of species. Trends Ecol. Evol., 21, 111-113.

Petit, R.J., Aguinalde, I., de Beaulieu, J.L., Bittkau, C., Brewer, S., Cheddadi, R. et al. (2003). Glacial refugia: hotspots but not melting pots of genetic diversity. Science, 300, 1563-1565.

Pisa, S., Biersma, E.M., Convey, P., Patiño, J., Vanderpoorten, A., Werner, O. et al. (2013). The cosmopolitan moss Bryum argenteum in Antarctica: back-colonization from extra-regional Pleistocene refugia or in-situ survival? Polar Biol., 37, 1469-1477.

Roads, E., Longton, R.E. \& Convey, P. (2014). Millenial timescale regeneration in a moss from Antarctica. Curr. Biol., 24, R222-R223.

Robert, C.P., Cornuet, J.M., Marin, J.M. \& Pillai, N.S. (2011). Lack of confidence in approximate Bayesian computation model choice. Proc. Natl Acad. Sci. USA, 108, 15112-15117.

Schönswetter, P., Paun, O., Tribsch, A. \& Niklfeld, H. (2003). Out of the Alps: colonization of Northern Europe by East Alpine populations of the Glacier Buttercup Ranunculus glacialis L. (Ranunculaceae). Mol. Ecol., 12, 3373-3381.

Schönswetter, P., Stehlik, I., Holderegger, R. \& Tribsch, A. (2005). Molecular evidence for glacial refugia of mountain plants in the European Alps. Mol. Ecol., 14, 3547-3555.

Schönswetter, P., Popp, M. \& Brochmann, C. (2006). Rare arctic-alpine plants of the European Alps have different immigration histories: the snow bed species Minuartia biflora and Ranunculus pygmaeus. Mol. Ecol., 15, 709-720.

Semerikov, V.L., Semerikova, S.A., Polezhaeva, M.A., Kosintsev, P.A. \& Lascoux, M. (2013). Southern montane populations did not contribute to the recolonization of West Siberian Plain by Siberian larch (Larix sibirica): a range-wide analysis of cytoplasmic markers. Mol. Ecol., 22, 4958-4971.
Skrede, I., Eidesen, P.B., Portela, R.P. \& Brochmann, C. (2006). Refugia, differentiation and postglacial migration in arctic-alpine Eurasia, exemplified by the mountain avens (Dryas octopetala L.). Mol. Ecol., $15,1827-1840$.

Stenøien, H.K., Shaw, A.J., Shaw, B., Hassel, K. \& Gunnarsson, U. (2011). North American origin and recent European establishment of the amphi-Atlantic peat moss Sphagnum angermanicum. Evolution, 65, $1181-1194$.

Sundberg, S. (2005). Larger capsules enhance short-range spore dispersal in Sphagnum, but what happens further away? Oikos, 108, 115-124.

Svenning, J.C., Normand, S. \& Kageyama, M. (2008). Glacial refugia of temperate trees in Europe: insights from species distribution modelling. J. Ecol., 96, 1117-1127.

Szövényi, P., Terracciano, S., Ricca, M., Giordano, S. \& Shaw, A.J. (2008). Recent divergence, intercontinental dispersal and shared polymorphism are shaping the genetic structure of amphi-Atlantic peatmoss populations. Mol. Ecol., 17, 5364-5377.

Szövényi, P., Sundberg, S. \& Shaw, A.J. (2012). Long-distance dispersal and genetic structure of natural populations: an assessment of the inverse isolation hypothesis in peat mosses. Mol. Ecol., 21, 5461-5472.

Thomé, M.T. \& Carstens, B.C. (2016). Phylogeographic model selection leads to insight into the evolutionary history of four-eyed frogs. Proc. Natl Acad. Sci. USA, 113, 8010-8017.

Tzedakis, P.C., Emerson, B.C. \& Hewitt, G.M. (2013). Cryptic or mystic? Glacial tree refugia in northern Europe. Trends Ecol. Evol., 28, 696-704.

Van der Velde, M. \& Bijlsma, R. (2003). Phylogeography of five Polytrichum species within Europe. Biol. J. Linn. Soc., 78, 203-213.

Vanderpoorten, A., Gradstein, S.R., Carine, M.A. \& Devos, N. (2010). The ghosts of Gondwana and Laurasia in modern liverwort distributions. Biol. Rev. Camb. Philos. Soc., 85, 471-487.

Wegmann, D., Leuenberger, C., Neuenschwander, S. \& Excoffier, L. (2010). ABCtoolbox: a versatile toolkit for approximate Bayesian computations. BMC Bioinformatics, 11, 116.

Westergaard, K.B., Alsos, I.G., Popp, M., Engelskjøn, T., Flatberg, K.I. \& Brochmann, C. (2011). Glacial survival may matter after all: nunatak signatures in the rare European populations of two west-arctic species. Mol. Ecol., 20, 376-393.

\section{SUPPORTING INFORMATION}

Additional supporting information may be found online in the Supporting Information section at the end of the article.

Editor, Francisco Lloret

Manuscript received 9 October 2018

First decision made 11 November 2018

Second decision made 30 January 2019

Manuscript accepted 24 February 2019 